\title{
Effects of skeletal muscle denervation on the potency of succinylcholine
}

\author{
HONG WANG, WEI FU, GANG LIU and SHI-TONG LI \\ Department of Anesthesiology, The First People's Hospital, School of Medicine, \\ Shanghai Jiaotong University, Shanghai 200030, P.R. China
}

Received December 15, 2014; Accepted September 1, 2015

DOI: $10.3892 / \mathrm{mmr} .2015 .4392$

\begin{abstract}
The aim of the present study was to investigate the time-dependent effects of denervation on the sensitivity of skeletal muscles to the relaxant succinylcholine $(\mathrm{SuCh})$ and to assess the possible association of the de novo expression of $\gamma$-acetylcholine receptor (AChR). Innervated as well as denervated mouse muscle cells and human embryonic kidney (HEK293) cells expressing $\gamma$-AChR and $\varepsilon$-AChR were used in the present study. The effects of $\mathrm{SuCh}$ on the current of nicotinic (n)AChRs were examined using a whole-cell patch clamp technique. Compared with innervated skeletal muscle cells, the SuCh concentration producing $50 \%$ of the maximal response $\left(\mathrm{EC}_{50}\right)$ were decreased by $20,56,73,66,60$ and $62 \%$ $(\mathrm{P}<0.05)$, and current responses induced by $30 \mu \mathrm{M} \mathrm{SuCh}$ were increased by 1.9-, 4.6-, 9.4-, 7.1-, 5.2- and 5.1-fold $(\mathrm{P}<0.05)$ at days $1,4,7,14,21$ and 28 after denervation, respectively. However, SuCh was equipotent regarding $\gamma$-AChR and $\varepsilon$-AChR $(\mathrm{P}>0.05)$. These results indicated that short-term denervation led to a change in the sensitivity of muscle cells to $\mathrm{SuCh}$, which, however, was unlikely to be associated with the de novo expression of $\gamma$-AChR.
\end{abstract}

\section{Introduction}

Succinylcholine ( $\mathrm{SuCh}$ ) is currently used in the clinic to achieve muscle relaxation, particularly when there is a demand for rapid onset and elimination of contraction. Due to its rapid onset, short half-life and reliably, $\mathrm{SuCh}$ treatment creates excellent intubation conditions. At present, no non-depolarizing relaxants that possess suitable pharmacodynamic characteristics for replacing $\mathrm{SuCh}$ are available $(1,2)$. Therefore, $\mathrm{SuCh}$ is most frequently applied prior to urgent tracheal intubation in the

Correspondence to: Professor Shi-Tong Li, Department of Anesthesiology, The First People's Hospital, School of Medicine, Shanghai Jiaotong University, 100 Haining Road, Shanghai 200030, P.R. China

E-mail: lishitong77@163.com

Key words: succinylcholine, denervation, skeletal muscle, nicotinic acetylcholine receptors, $\gamma$-acetylcholine receptor peri-operative period, at intensive care units and emergency departments, and even outside the hospital during emergency transportation of patients (3-6).

However, thermal injury and other forms of critical tissue damage can cause denervation-associated changes in skeletal muscles (7). Denervated skeletal muscle displays two characteristic changes: An increase in the number of nicotinic acetylcholine receptors (nAChRs) and de novo expression of fetal-type $n A C h R(\gamma$-AChR) (8). Upregulation of nAChRs results in increased sensitivity to $\mathrm{SuCh}$ and resistance to non-depolarizing relaxants (7-11). Certain studies reported that after denervation, levels of $\mathrm{nAChR}$ and $\gamma$-AChR changed with time; furthermore, the $\mathrm{IC}_{50}$ of $d$-tubocurarine (dTC) correlated positively with nAChR and $\gamma$-AChR mRNA levels at different time-points after denervation (12-14). All of theses results indicated that the potency of muscle relaxants may change with increasing time of skeletal muscle denervation.

The aim of the present study was to assess the changes in the potency of SuCh during the first month after denervation in a mouse model. Furthermore, the present study investigated whether the de novo expression of $\gamma$-AChR contributed to the increased sensitivity of denervated skeletal muscles to $\mathrm{SuCh}$.

\section{Materials and methods}

Denervation. The present study was approved by the Animal Care and Use Committee of Bengbu Medical School. Balb/C mice (35 days old) were anesthetized with pentobarbital, (40 mg/kg intraperitoneally). A sample of a few millimeters in size of the right sciatic nerve was excised through a small (3-5 $\mathrm{mm}$ ) incision above the hip. The incision was sutured with a single stitch. Animals were sacrificed at 1, 4, 7, 14, 21 and 28 days after denervation by pentobarbital anesthesia and cervical dislocation. Animals that had received surgery without incision of the sciatic nerve were used as the innervated control ( 0 days after denervation).

Isolation of muscle fibres. Single skeletal muscle cells from the flexor digitorum brevis (FDB) muscle were obtained from the hindfeet of the mice. The muscles were incubated for $3 \mathrm{~h}$ with Dulbecco's modified Eagle's medium (DMEM; Invitrogen Life Technologies, Carlsbad, CA, USA) containing $10 \%$ fetal calf serum (FCS; Invitrogen Life Technologies), $100 \mathrm{U} / \mathrm{ml}$ penicillin (Sigma-Aldrich, St. Louis, MO, USA), 
$100 \mu \mathrm{g} / \mathrm{ml}$ streptomycin (Sigma-Aldrich) and $0.2 \%$ collagenase $1 \mathrm{~A}$ (Sigma-Aldrich) with agitation at $37^{\circ} \mathrm{C}$. Subsequently, flexor digitorum brevis (FDB) muscles were disaggregated into single muscle cells by repetitive pipetting using Pasteur pipettes of various tip sizes.

Expression of nAChR in human embryonic kidney (HEK)293

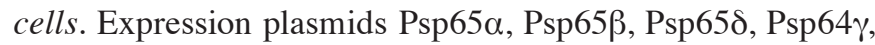
and Pbssk $(+) \varepsilon$, encoding complementary DNA-coding sequences for the mouse muscle nAChR sub-units $\alpha, \beta, \delta, \gamma$ and $\varepsilon$, respectively, were provided by the Salk Institute for Biological Studies (La Jolla CA, USA). These plasmids were sub-cloned into pcDNA3.1+ (Invitrogen Life Technologies). HEK293 cells (Shanghai Institute of Biochemistry and Cell Biology for Biological Sciences, Shanghai, China) were cultured in DMEM supplemented with $10 \%$ FCS, $100 \mathrm{U} / \mathrm{ml}$ penicillin and $100 \mu \mathrm{g} / \mathrm{ml}$ streptomycin at $37^{\circ} \mathrm{C}$ in an incubator containing $5 \% \mathrm{CO}_{2}$. The HEK293 cells were stably transfected with Lipofectamine ${ }^{\mathrm{TM}} 2000$ (Invitrogen Life Technologies) according to the manufacturer's instructions. After transfection, positive cell clones were selected with G418 (Invitrogen Life Technologies). The transfected cells were then incubated for $24 \mathrm{~h}$ prior to being subjected to the electrophysiological assays.

Electrophysiology. FDB muscle cells or HEK293 cells were voltage-clamped using a whole-cell patch clamp technique (15). All experiments were performed at room temperature $\left(20-24^{\circ} \mathrm{C}\right)$. Patch pipettes were pulled from borosilicate glass using a Flaming Brown micropipette puller (P97; Sutter Instrument Co., Novato, CA, USA), ranging from 1-2 M $\Omega$. The pipette electrode was filled with the following solution: $140 \mathrm{mM} \mathrm{KCl}, 10 \mathrm{mM}$ 4-(2-hydroxyethyl)-1-piperazineethanesulfonic acid (HEPES), $10 \mathrm{mM}$ ethylene glycol tetraacetic acid, $1 \mathrm{mM} \mathrm{CaCl}$ and $1 \mathrm{mM} \mathrm{MgCl}$; the $\mathrm{pH}$ was adjusted to 7.2 with $\mathrm{KOH}$. The external solution contained $5 \mathrm{mM} \mathrm{KCl}, 140 \mathrm{mM} \mathrm{NaCl}, 1 \mathrm{mM} \mathrm{CaCl}{ }_{2}, 1.25 \mathrm{mM} \mathrm{MgCl}_{2}$, $10 \mathrm{mM}$ HEPES, $10 \mathrm{mM}$ glucose and $0.5 \mu \mathrm{M}$ atropine sulfate, and the $\mathrm{pH}$ was adjusted to 7.4 with $\mathrm{NaOH}$. The cells were voltage-clamped at $-80 \mathrm{mV}$ in a whole-cell configuration after obtaining $\mathrm{G} \Omega$ seals. A major amount of the series resistance (60-80\%) was compensated. Currents were recorded with an EPC10 amplifier (HEKA Elektronik, Lambrecht, Germany) and PatchMaster software (v2.15; HEKA Eletronik), sampled at $10 \mathrm{kHz}$.

$\mathrm{SuCh}$ (Sigma-Aldrich) was dissolved in the external solution and applied via a gravity-driven perfusion system. Solutions and subsequent dilutions were prepared immediately prior to the experiments.

Test solution applications containing various concentrations of SuCh (1-500 $\mu \mathrm{M})$ were applied for $10 \mathrm{sec}$ to the skeletal muscle cells obtained from mice sacrificed on days 0 , 1, 4, 7, 14, 21 and 28 after denervation or to HEK293 cells for $5 \mathrm{sec}$, and the peak current was determined. The washout time between each drug application was at least $60 \mathrm{sec}$ in order to minimize the amount of desensitization throughout the course of an experiment. Currents were acquired from five skeletal muscle cells taken from at least two mice or five HEK293 cells.

Statistical analysis. Data analysis was performed off-line using Origin 8 (OriginLab, Northampton, MA, USA) and
GraphPad Prism 4 (Graphpad Software, Inc., La Jolla, CA, USA). Concentration-response curves were fitted to the four-parameter logistic equation by non-linear regression analysis, and the $\mathrm{EC}_{50}$ was calculated as the concentration of the agonist eliciting a half-maximal response. Values are expressed as the mean \pm standard deviation. Statistical significance was assessed by one-way analysis of variance followed by Tukey's test or unpaired two-tailed Student's t-tests. $\mathrm{P}<0.05$ was considered to indicate a statistically significant difference between values.

\section{Results}

SuCh at various concentration $(1-500 \mu \mathrm{M})$ was applied for $10 \mathrm{sec}$ to mouse skeletal muscle cells on days $0,1,4,7,14,21$, and 28 after denervation. SuCh elicited concentration-dependent inward currents (Figs. 1 and 2). The data were fitted to a logistic equation. The $\mathrm{SuCh}$ concentration producing $50 \%$ of the maximal response $\left(\mathrm{EC}_{50}\right)$ was $27.5 \mu \mathrm{M}$ for the $\mathrm{nAChR}$ in the innervated skeletal muscle (day 0 after denervation). Compared with the $\mathrm{EC}_{50}$ value at day 0 after denervation, the $\mathrm{EC}_{50}$ values were decreased by 20 ( $\left.\mathrm{P}>0.05\right), 56,73,66,60$ and $62 \%(\mathrm{P}<0.05)$ on days $1,4,7,14,21$ and 28 after denervation, respectively (Fig. 3).

Application of $30 \mu \mathrm{M}$ SuCh produced inward currents with different amplitudes at the nAChRs of skeletal muscle cells on days $0,1,4,7,14,21$ and 28 after denervation (Fig. 4). Compared with the current responses on day 0 after denervation, the current responses induced by $30 \mu \mathrm{M} \mathrm{SuCh}$ were increased by 1.9-, 4.6-, 9.4-, 7.1-, 5.2- and 5.1-fold $(\mathrm{P}<0.05)$ at days $1,4,7,14,21$ and 28 after denervation, respectively (Fig. 5).

To further determine the effects of SuCh on nAChR sub-types, HEK293 cells were stably transfected with plasmids expressing either $\varepsilon$ - or $\gamma$-AChR and then treated with $\mathrm{SuCh}$. SuCh elicited currents in the HEK293 cells in a concentration-dependent manner (Fig. 6). However, comparison of the $\mathrm{EC}_{50}$ values revealed that no significant differences were present between the effects of $\mathrm{SuCh}$ on currents in $\varepsilon$-AChRand $\gamma$-AChR-expressing HEK293 cells (P>0.05) (Fig. 7).

\section{Discussion}

The present study determined the effects of short-term denervation on the sensitivity of skeletal muscles to SuCh. As previous studies have indicated the amount of membrane $\mathrm{nAChR}$ after denervation changed with time $(7,8)$, the present study further assessed whether the increased sensitivity to $\mathrm{SuCh}$ after denervation was associated with the presence of $\gamma$-AChR.

The present study generated a murine denervation model according to methods of previous studies by our group $(7,8,11)$. Innervated and denervated skeletal muscle cells were obtained at various time-points after denervation. Compared with the values obtained from innervated skeletal muscle cells, the potency of SuCh significantly increased at day 4, peaked at day 7 and declined by day 14 . Ibebunjo and Martyn $(12,16)$ demonstrated that burn injuries induced increases in $\mathrm{nAChRs}$ at days 4, 7 and 14 in rat skeletal muscles. Furthermore, Adams et al (14) reported that denervation increased the 

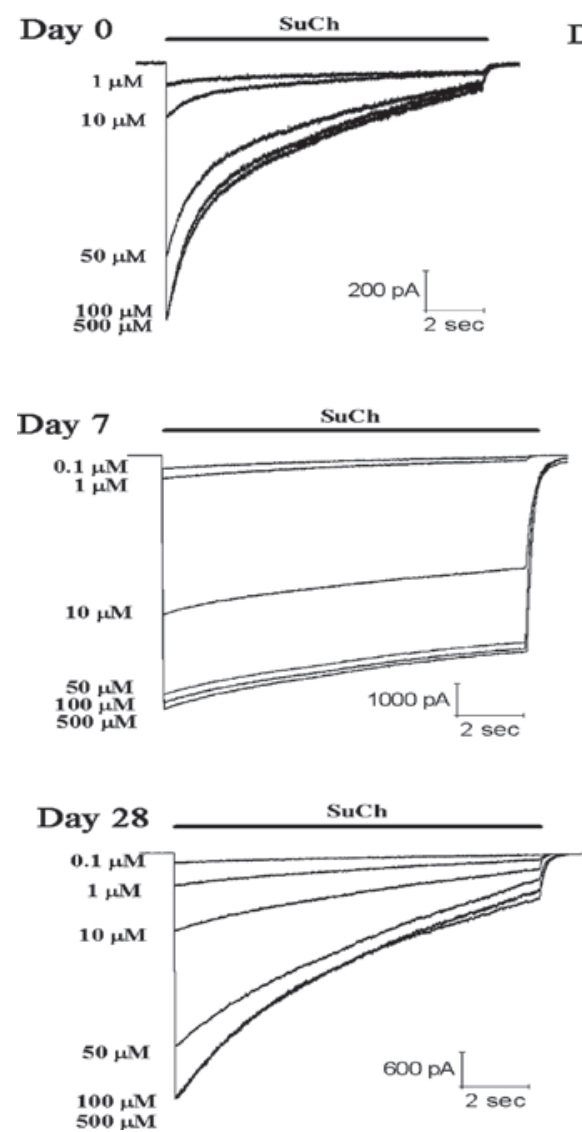
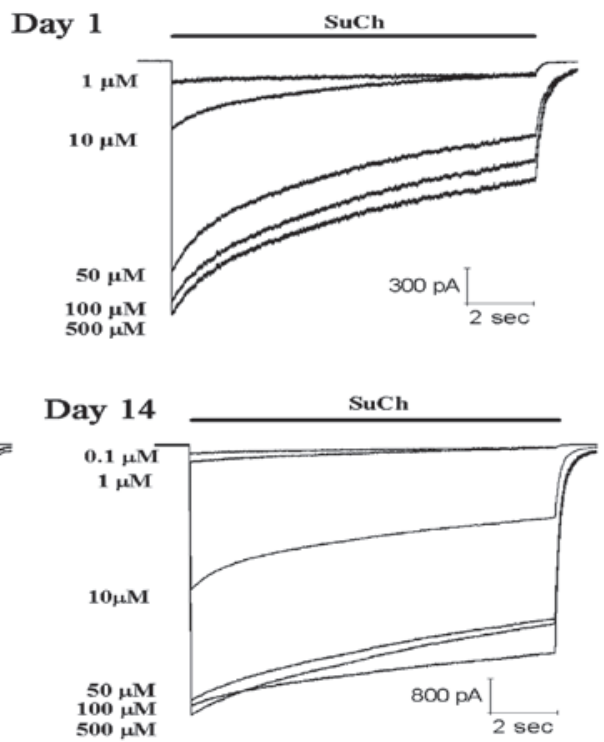
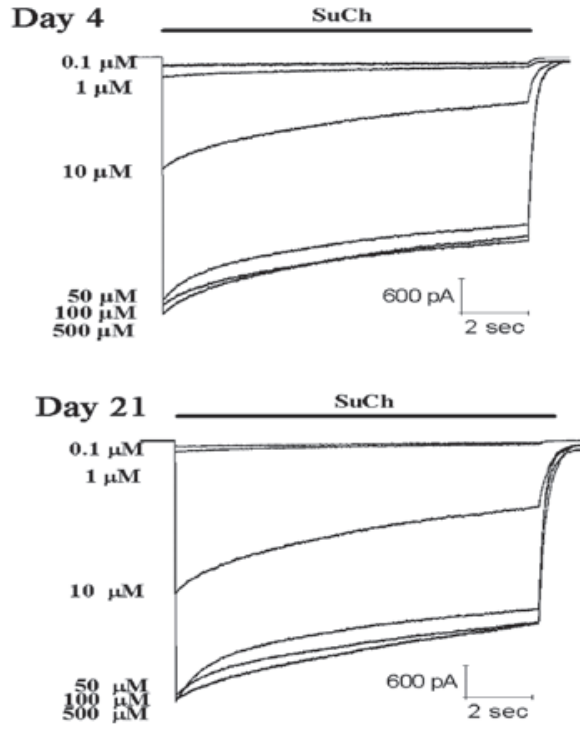

Figure 1. Concentration-dependent effects of SuCh on nicotinic acetylcholine receptors in denervated muscle cells at days $0,1,4,7,14,21$ and 28 after denervation. SuCh, succinylcholine.

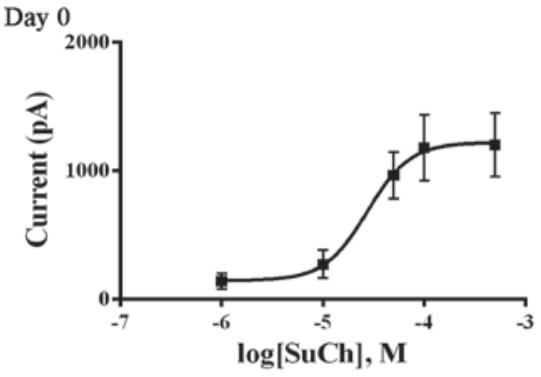

Day 7
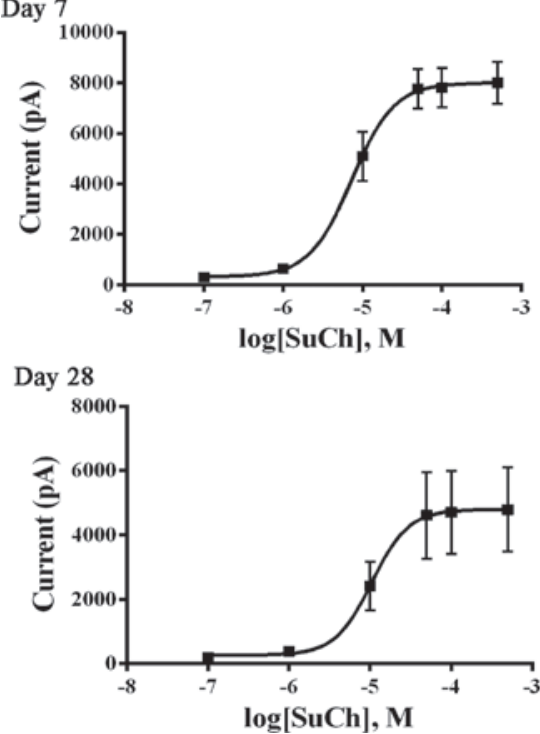

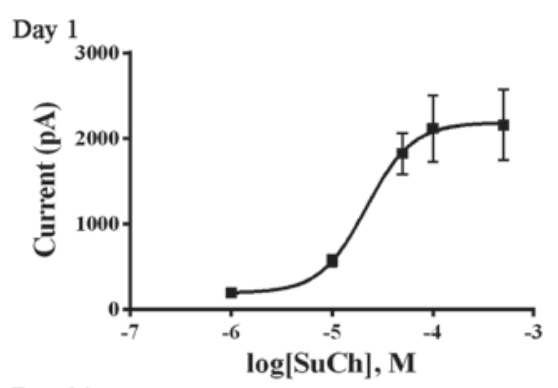

Day 14

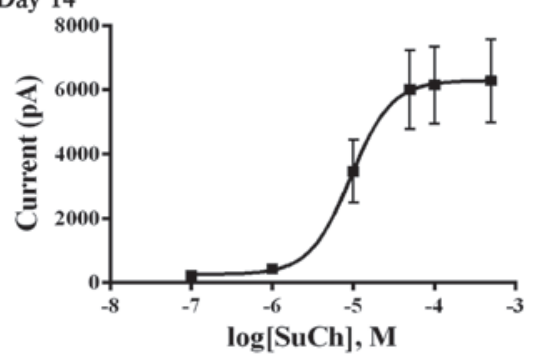

Day 4

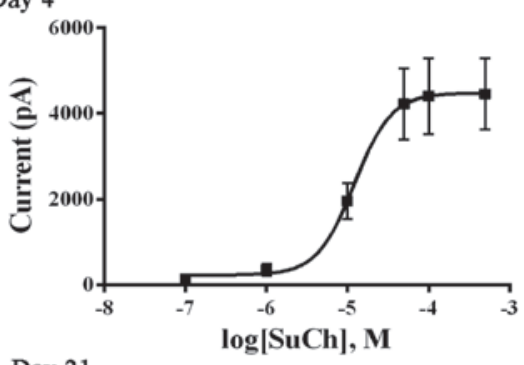

Day 21

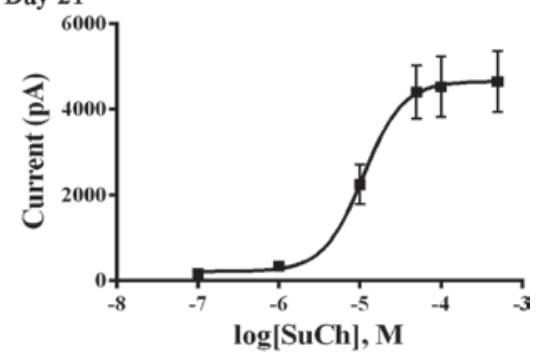

Figure 2. Concentration-response curve for the action of SuCh on nicotinic acetylcholine receptors in skeletal muscle cells at days $0,1,4,7,14,21$ and 28 after denervation $(\mathrm{n}=5)$. Values are expressed as the mean \pm standard deviation. SuCh, succinylcholine. 


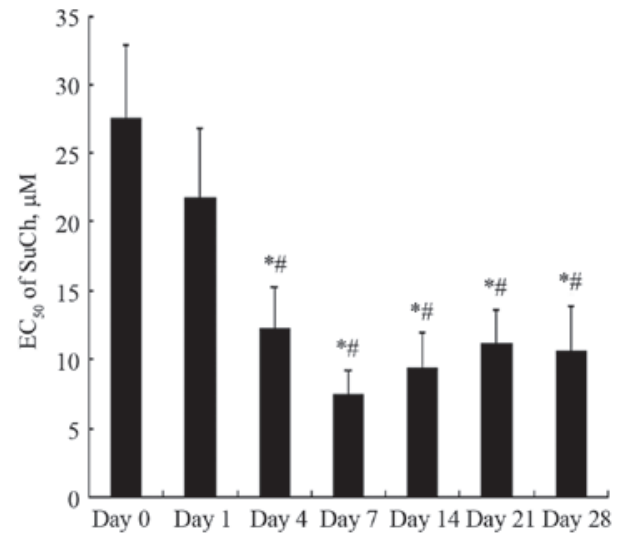

Figue 3. $\mathrm{EC}_{50}$ of $\mathrm{SuCh}$ in skeletal muscle cells at days $0,1,4,7,14,21$ and 28 after denervation $(n=5)$. Values are expressed as the mean \pm standard deviation. ${ }^{\mathrm{P}}<0.05$ vs. day $0 ;{ }^{*} \mathrm{P}<0.05$ vs. day 1 . SuCh, succinylcholine.
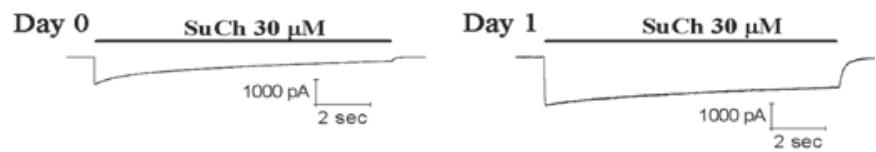

Day 4

SuCh $30 \mu \mathrm{M}$

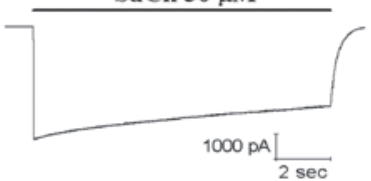

Day 14

SuCh $30 \mu \mathrm{M}$

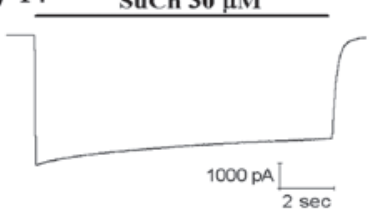

Day 7

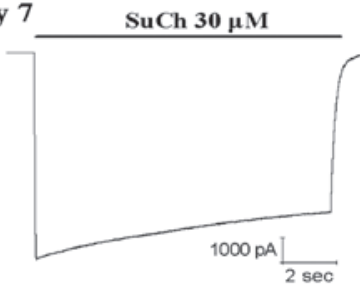

Day 21

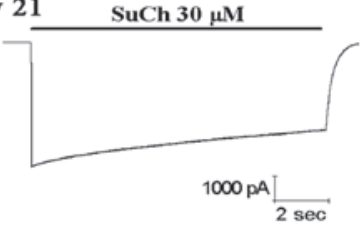

Day 28 SuCh $30 \mu \mathrm{M}$

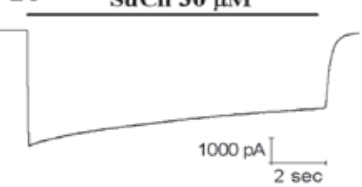

Figure 4. Inward currents were elicited by $30 \mu \mathrm{M}$ SuCh on skeletal muscle cells at days $0,1,4,7,14,21$ and 28 after denervation. SuCh, succinylcholine.

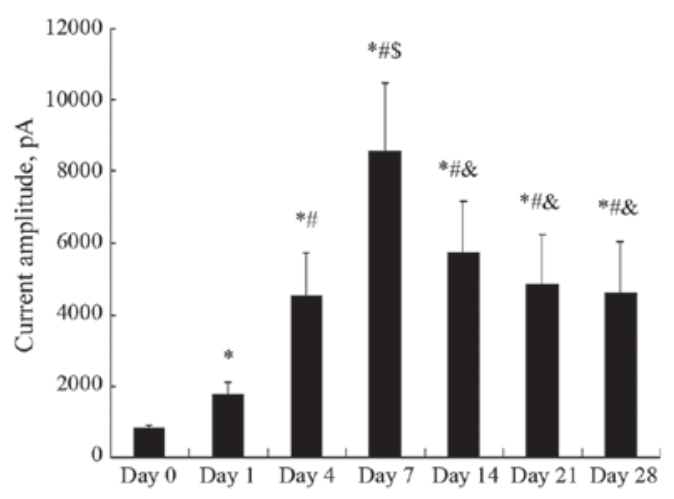

Figure 5. Inward currents were elicited by $30 \mu \mathrm{M}$ succinylcholine on skeletal muscle cells at days $0,1,4,7,14,21$ and 28 after denervation $(n=5)$. Values are expressed as the mean \pm standard deviation. ${ }^{*} \mathrm{P}<0.05$ vs. day $0 ;{ }^{~} \mathrm{P}<0.05$ vs day $1 ;{ }^{\$} \mathrm{P}<0.05$ vs. day $4 ;{ }^{\&} \mathrm{P}<0.05$ vs. day 7 .

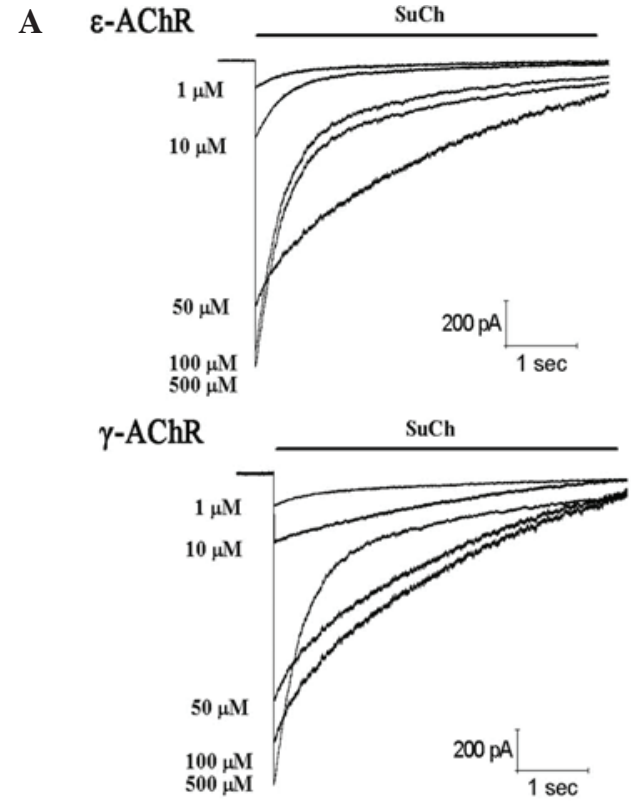

B
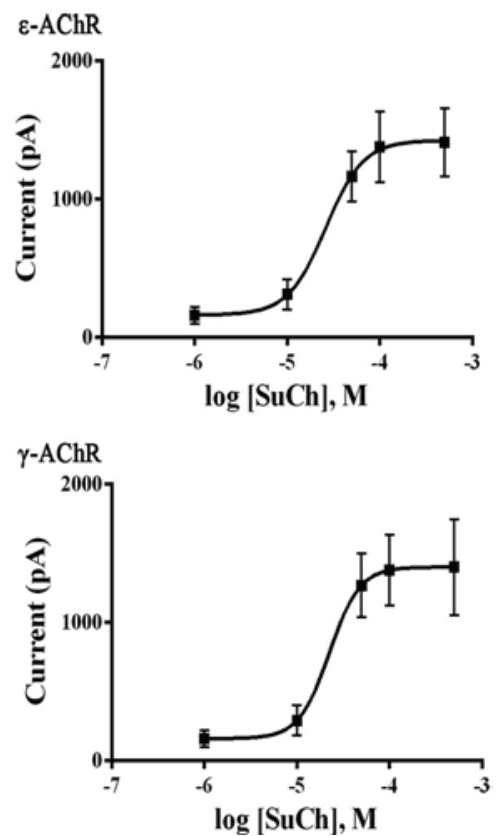

Figure 6. SuCh produced concentration-dependent inward currents in adult-type $(\varepsilon)$ and fetal-type $(\gamma)$ AChRs expressed in HEK293 cells (A) Representative recording of currents produced by 1, 10, 50, 100 and $500 \mu \mathrm{M} \mathrm{SuCh}$ (horizontal bars). (B) Concentration-response curve for the action of $\mathrm{SuCh}$ on $\varepsilon$-AChR and $\gamma$-AChR. Values are expressed as the mean \pm standard deviation of five HEK 293 cells. SuCh, succinylcholine; $\mathrm{nAChR}$, nicotinic acetylcholine receptor.

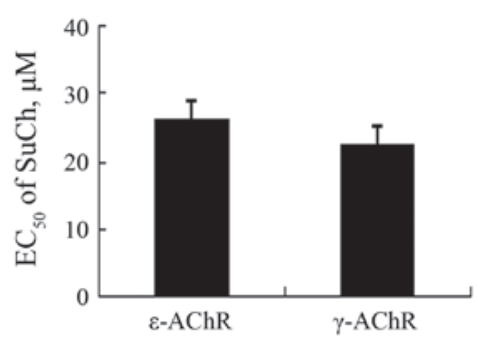

Figure 7. $\mathrm{EC}_{50}$ of $\mathrm{SuCh}$ in $\varepsilon$-AChR and $\gamma$-AChR expressed in HEK293 cells. Values are expressed as the mean \pm standard deviation. SuCh, succinylcholine; $\mathrm{AChR}$, acetylcholine receptor. 
expression of all sub-unit genes of nAChRs during the first month of denervation. Furthermore, previous studies by our group have confirmed that short-term muscle denervation leads to a changing pattern of resistance to non-depolarizing muscle relaxants that can be attributed to upregulation of mature and immature nAChRs on the muscular membrane $(8,11)$.

The present study assessed the activated current amplitude following application of $30 \mu \mathrm{M} \mathrm{SuCh}$ on $\mathrm{nAChRs}$ in innervated and denervated skeletal muscle. Compared with that in innervated skeletal muscle cells, the current amplitude after denervation was significantly increased. The time-course of increases in the current amplitude after denervation was similar to that of the $\mathrm{EC}_{50}$ of SuCh. Consistent with the results of the present study, a previous study on the denervation of a single limb, a hyperkalemic response to SuCh occurred as early as on day four after denervation (17). Therefore, Gronert (18) suggested that it is advisable to avoid the use of $\mathrm{SuCh}$ beyond 48-72 $\mathrm{h}$ of denervation.

nAChRs include two sub-types: The adult form ( $\varepsilon-\mathrm{AChR})$ composed of $\alpha_{2} \beta \delta \varepsilon$ sub-units and the fetal form ( $\gamma$-AChR) containing $\alpha_{2} \beta \delta \gamma$ sub-units (7). Only $\varepsilon$-AChR is expressed in adult muscle; however, denervation results in the de novo expression of $\gamma$-AChR (19). Ibebunjo (12) reported that resistance to dTC is associated with the expression of $\gamma$-AChR. In addition, a previous study by our group demonstrated that the phenomenon of different magnitudes of resistance to non-depolarizing muscle relaxants in denervated mouse skeletal muscles is due to the different potencies of individual non-depolarizing muscle relaxants with regard to $\mathrm{nAChR}$ sub-units (7). The present study examined the effects of SuCh on currents in HEK293 cells heterologously expressing $\varepsilon$-AChR or $\gamma$-AChR. The results showed that SuCh had equipotent effects on cells expressing either of the receptor sub-types. Similarly, Yost and Winegar (20) reported that there were no significant differences in the $\mathrm{EC}_{50}$ for $\mathrm{SuCh}$ on $\varepsilon$-AChR and $\gamma$-AChR, and that $\varepsilon$-AChR had a six- to eight-fold higher intrinsic activity for SuCh than $\gamma$-AChR. The results of the present study therefore indicated that the changes in sensitivity of muscle cells to SuCh after denervation are not associated with the de novo expression of $\gamma$-AChR.

In conclusion, the present study found that short-time denervation resulted an increased sensitivity of muscle cells to $\mathrm{SuCh}$, which is unlikely to be associated with the de novo expression of $\gamma$-AChR. After denervation, the potency of SuCh significantly increased by day 4 , peaked at day 7 , declined by day 14 and remained constant until day 28 . These results suggested that it is advisable to avoid the use of SuCh at day 4 after denervation and thereafter in order to prevent lethal hyperkalemic responses.

\section{Acknowledgements}

The present study was supported by the National Natural Science Foundation of China (no. 30571796).

\section{References}

1. Miller R: Will succinylcholine ever disappear? Anesth Analg 98: 1674-1675, 2004

2. Caldwell JE: The continuing search for a succinylcholine replacement. Anesthesiology 100: 763-764, 2004.

3. Laurin EG, Sakles JC, Panacek EA, Rantapaa AA and Redd J: A comparison of succinylcholine and rocuronium for rapid-sequence intubation of emergency department patients. Acad Emerg Med 7: 1362-1369, 2000.

4. Marsch SC, Steiner L, Bucher E, Pargger H, Schumann M, Aebi T, Hunziker PR and Siegemund M: Succinylcholine versus rocuronium for rapid sequence intubation in intensive care: A prospective, randomized controlled trial. Crit Care 15: R199, 2011.

5. Norwood S, Myers MB and Butler TJ: The safety of emergency neuromuscular blockade and orotracheal intubation in the acutely injured trauma patient. J Am Coll Surg 179: 646-652, 1994.

6. Ma OJ, Atchley RB, Hatley T, Green M, Young J and Brady W: Intubation success rates improve for an air medical program after implementing the use of neuromuscular blocking agents. Am J Emerg Med 16: 125-127, 1998.

7. Wang H, Yang B, Xu YF, Yan T and Li ST: Different magnitude of resistance to nondepolarizing muscle relaxants in the denervated mouse skeletal mucle. Acta Pharmacol Sin 31: 399-404, 2010.

8. Wang H, Yang B, Han GW and Li ST: Potency of nondepolarizing muscle relaxants at muscle-type acetylcholine receptors in denervated mouse skeletal muscle. Acta Pharmacol Sin 31: 1541-1546, 2010.

9. Martyn JA, White DA, Gronert GA, Jaffe RS and Ward JM: Up-and-down regulation of skeletal muscle acetylcholine receptors. Effects on neuromuscular blockers. Anesthesiology 76: 822-843, 1992.

10. Yanez P and Martyn JA: Prolonged d-tubocurarine infusion and/or immobilization cause upregulation of acetylcholine receptors and hyperkalemia to succinylcholine in rats. Anesthesiology 84: 384-391, 1996.

11. Wang H, Liang QS and Cheng LR: Effects of skeletal muscle denervation on potency of rocuronium. Asian Biomedicine 5: 507-512, 2011.

12. Ibebunjo C and Martyn JA: Thermal injury induces greater resistance to d-tubocurarine in local rather than in distant muscles in the rat. Anesth Analg 91: 1243-1249, 2000.

13. Ma J, Shen J, Garrett JP, Lee CA, Li Z, Elsaidi GA, Ritting A, Hick J, Tan KH, Smith TL, et al: Gene expression of myogenic regulatory factors, nicotinic acetylcholine receptor subunits, and GAP-43 in skeletal muscle following denervation in a rat model. J Orthop Res 25: 1498-1505, 2007.

14. Adams L, Carlson BM, Henderson L and Goldman D: Adaptation of nicotinic acetylcholine receptor, myogenin and MRF4 gene expression to long-term muscle denervation. J Cell Biol 131: 1341-1349, 1995.

15. Hamill OP, Marty A, Neher E, Sakmann B and Sigworth FJ: Improved patch-clamp techniques for high-resolution current recording from cells and cell-free membrane patches. Pflugers Arch 391: 85-100, 1981.

16. Ibebunjo C and Martyn J: Disparate dysfunction of skeletal muscles located near and distant from burn site in the rat. Muscle Nerve 24: 1283-1294, 2001.

17. John DA, Tobey RE, Homer LD and Rice CL: Onset of succinylcholine-induced hyperkalemia following denervation. Anesthesiology 45: 294-299, 1976.

18. Gronert GA: Succinylcholine hyperkalemia after burns. Anesthesiology 91: 320-322, 1999.

19. Witzemann V, Brenner HR and Sakmann B: Neural factors regulate AChR subunit mRNAs at rat neuromuscular synapses. J Cell Biol 114: 125-141, 1991.

20. Yost CS and Winegar BD: Potency of agonists and competitive antagonists on adult- and fetal-type nicotinic acetylcholine receptors. Cell Mol Neurobiol 17: 35-50, 1997. 